\title{
Integrasi Database DISDUKCAPIL dan Database KPU Kabupaten Maros Memanfaatkan Web Services
}

\author{
Frans N. Allokendek*1, John Soetikno ${ }^{2}$, Ahmad Ashari ${ }^{3}$ \\ ${ }^{1,2}$ STMIK Dipanegara Makassar; Jl. Perintis Kemerdekaan KM. 9, Makassar telp. 0411-587194 \\ ${ }^{3}$ Jurusan Ilmu Komputer dan Elektronika, FMIPA UGM, Yogyakarta \\ e-mail: *1. fnurmianto@yahoo.com, ${ }^{2}$ jo_dipanegara@yahoo.com, ${ }^{3}$ ashari@ugm.ac.id
}

\begin{abstract}
Abstrak
Banyaknya permasalahan yang ditemukan dalam pelaksanaan Pemilukada, baik yang disebabkan oleh penyelenggara maupun oleh peserta.Permasalahan yang sering terjadi adalah tidak tersedianya data daftar penduduk potensi pemilih pilkada (DP4) yang ter-update, penggelembungan jumlah pemilih karena adanya data ganda, dan terbatasnya waktu untuk memverifikasi dokumen.Permasalahan yang serupa yang dihadapi oleh KPU Maros ditambah dengan terbatasnya sarana/media publikasi yang disediakan oleh KPU Maros dalam menginformasikan DPS dan DPT kepada masyarakat.

Web service adalah sebuah teknologi yang meliputi sekumpulan standar yang memungkinkan dua aplikasi komputer dapat saling berkomunikasi dan bertukar data di internet. Teknologi web services menawarkan kecepatan dan kemudahan dalam mendapatkan informasi dari berbagai sumber tanpa mempermasalahkan perbedaan teknologi yang digunakan. Dalam penelitian ini, web service digunakan untuk mengkomunikasikan dua aplikasi yang berbeda yaitu SIAK DISDUKCAPIL Kabupaten Maros dan SIDP KPU Kabupaten Maros.

Penelitian ini dilanjutkan dengan membuat suatu desain sistem dan implementasi berupa prototype sistem yang mengintegrasikan data dari database SIAK DISDUKCAPIL dengan database KPU di Kabupaten Maros dengan memanfaatkan teknologi web services. Hasilnya adalah didapatnya DPT yang valid serta adanya alternatif lain dalam mempublikasikan DPT kepada masyarakat, disamping tetap menggunakan media publikasi yang telah digunakan selama ini.
\end{abstract}

Kata kunci-Web Services, Integrasi Data, DPT

\begin{abstract}
Many problems are encountered in the implementation of Local Election, which are caused by both the committee and participants. The problems that frequently occurred are the unavailability of data on the list of updated potential population to be voters in Local Election, the swallowing number of voters due to double data, and the limited time to verify documents. The similar problems that are encountered by General Election Committee of Maros Regency.

Web service is a technology that includes a set of standards allowing two computer applications that can communicate with each other and exchange data in Internet. In the study, web services are used to communicate two different applications: SIAK of the Demography and Civil Registration Office of Maros Regency and SIDP of the General Election Committee of Maros Regency.

The study is followed by making the design of system and implementation such as a prototype data integration system between the database of SIAK of the Demography and Civil Registration Office of Maros Regency and that of General KPU in Maros Regency by utilizing web service technology. The result is the valid Fixed Voter List.
\end{abstract}

Keywords-Web Services, Data Integration, Fixed Voter List

Received November $1^{\text {st }}$,2012; Revised December $1^{\text {st }}$, 2012; Accepted December 15 ${ }^{\text {th }}$, 2012 


\section{PENDAHULUAN}

$\mathrm{D}^{\prime}$ alam pelaksanaan Pemilu/Pilkada, Komisi Pemilihan Umum (KPU) [1] dibantu oleh Pemerintah dalam hal penyediaan data penduduk yang nantinya akan dijadikan acuan pembuatan DPT. Dinas Kependudukan dan Pencatatan Sipil (DISDUKCAPIL) yang dalam hal ini sebagai wakil pemerintah, melakukan kegiatan administrasi kependudukan yang setiap harinya terjadi transaksi data yang cukup tinggi, beberapa jenis transaksi diantaranya adalah adanya urusan administrasi berkaitan dengan mobilisasi warga (Surat Pindah domisili) dengan berbagai alasan dan keperluan, adanya penduduk yang menikah (Akta Perkawinan), dan adanya warga yang meninggal dunia (Akta Kematian) [2]. Dari ketiga jenis transaksi data kependudukan tersebut itulah yang sangat mempengaruhi Daftar Penduduk Potensial Pemilih Pemilu (DP4) yang nantinya menjadi dasar pembuatan Daftar Pemilih Tetap (DPT) [3].

Tingkat validasi dan akurasi DPT yang dibuat oleh KPU beserta jajarannya, ternyata sangat rendah. Apabila diamati secara lebih mendalam, penyebab utama terjadinya kekisruhan dalam DPT tersebut, adalah bahwa sampai sekarang belum adanya administrasi kependudukan yang tertata dengan baik dan KPU sebagai penyelenggara Pemilu belum mampu memilhara data pemilih secara berkesinambungan [4].

Demikian juga yang terjadi di lingkup KPU Propinsi Sulawesi Selatan, salah satunya adalah KPU Kabupaten Maros, ditambah dengan terbatasnya sarana/media publikasi yang disediakan oleh KPU Maros dalam menginformasikan daftar pemilih sementara (DPS), DPS hasil perbaikan dan DPT kepada masyarakat agar dapat dikoreksi secara cepat.

Dengan banyaknyapermasalahan tersebut, maka muncullah gagasan untuk mendapatkan DP4 dengan memanfaatkan teknologi yang ada, khususnya Web Services.Hal ini didukung dengan semakin luasnya jaringan komunikasi dan biaya komunikasi yang semakin murah.Pada penelitian ini, solusi lebih difokuskan pada integrasi data penduduk pada DISDUKCAPIL dengan data pemilih pada KPU di Kabupaten Maros. Dengan adanya dua sistem atau lebih yang akan dikomunikasikan, keadaan tersebut dapat menimbulkan masalah dalam proses pertukaran data antar perangkat yang menggunakan aplikasi dan platform yang berbeda. Namun proses integrasi data ini memanfaatkan teknologi Web Services yang memiliki kelebihan utama dalam hal memangkas kendala dalam hal teknologi, jarak, ruang dan waktu.

Berdasarkan latar belakang di atas, maka dirumuskan beberapa masalah, yaitu :

1. Apa syarat model dalam web service pada prototipe integrasi data penduduk daftar pemilih tetap (DPT) agar dapat digunkan untuk mendapatkan DP4, DPS, dan DPT yang valid.

2. Bagaimana membuat model integrasi data penduduk daftar pemilh tetap yang memenuhi persyaratan penetepan DPT yang baik serta mampu menutup kelemahan yang muncul pada penetapan DPT secara konvensional.

3. Bagaimana membuat prototipe integrasi data penduduk daftar pemilih tetap yang mampu mendapatkan DP4, DPS, dan DPT yang valid untuk digunakan dalam verifikasi pemilih.

4. Bagaimana melakukan pengujian terhadap metode yang telah dibuat.

\section{METODE PENELITIAN}

\subsection{Web Services}

Sebuah Web Services adalah aplikasi perangkat lunak yang dapat diakses dari jarak jauh menggunakan bahasa berbeda berbasis XML (eXtensible Markup Language) [5].Teknologi Web Services menawarkan kemudahan dalam menjembatani sumber-sumber informasi tanpa mempermasalahkan perbedaan teknologi yang digunakan ditiap sumber. Misalkan sebuah situs informasi dibangun dengan menggunakan database Oracle sedangkan situs lainya menggunakan Mysql, maka aplikasi Web Services akan mengatasi perbedaan ini. Web Services diperlukan karena pada masa sekarang ini perangkat keras, sistem operasi, aplikasi hingga bahasa pemrograman semakin beraneka ragam jenisnya. Keadaan tersebut dapat menimbulkan masalah

IJCCS Vol. 7, No. 1, January 2013: $1-12$ 
dalam proses pertukaran data antar perangkat yang menggunakan aplikasi dan platform yang berbeda.

Web Services klien mengirim dokumen XML diformat dengan cara khusus sesuai dengan aturan dari spesifikasi SOAP (Simple Object Access Protocol). Sebuah pesan SOAP dapat berisi panggilan ke metode bersama dengan parameter yang mungkin dibutuhkan.Selain itu, pesan dapat mengandung sejumlah item header yang lebih spesifikasi untuk lebih menjelaskan maksud dari klien. Item ini didesain untuk menunjukan apa yang akan Web Services dapatkan setelah layanan yang aktif selesai melakukan pekerjaannya dengan memanggil metode, atau mereka mungkin berisi informasi keamanan. Dalam kasus apapun, kompleksitas dari pesan SOAP jauh melebihi kompleksitas yang mungkin hanya menggunakan browser [5].

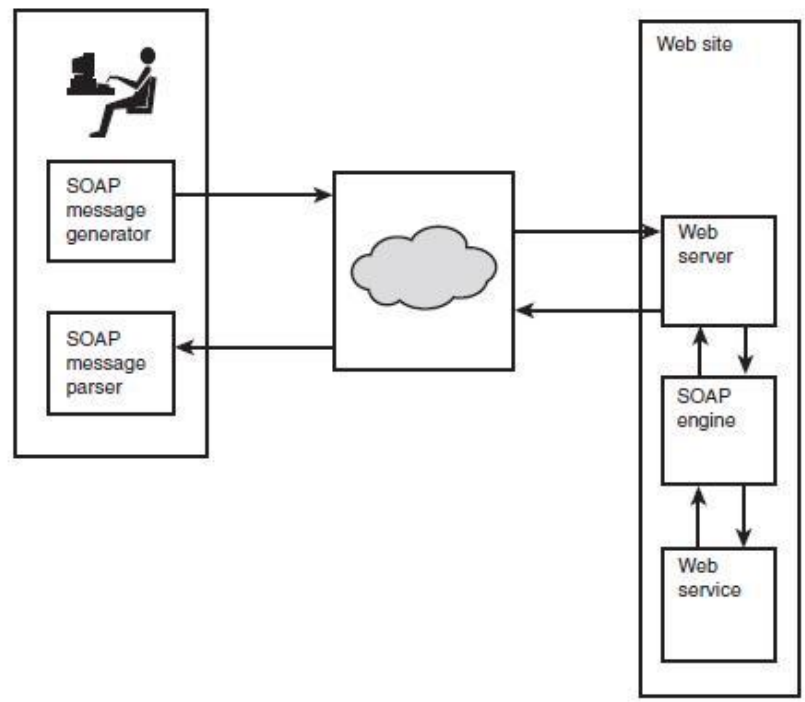

Gambar 1 Sistematika Web Service [5]

Dari Gambar 1 Web service pada dasarnya menggunakan protocol standar HTTP (hypertext transfer protocol) dan SOAP untuk membuat sebuah data manjadi tersedia dalam web.

\subsubsection{Arsitektur Web Service}

Arsitektur web service memiliki tiga entitas dalam arsitekturnya, yaitu Service Rquester (permintaan layanan), Service Provider (penyedia layanan), dan Service Registry (daftar layanan) [6].Arsitektur umum web service tersebut disajikan pada Gambar 2.

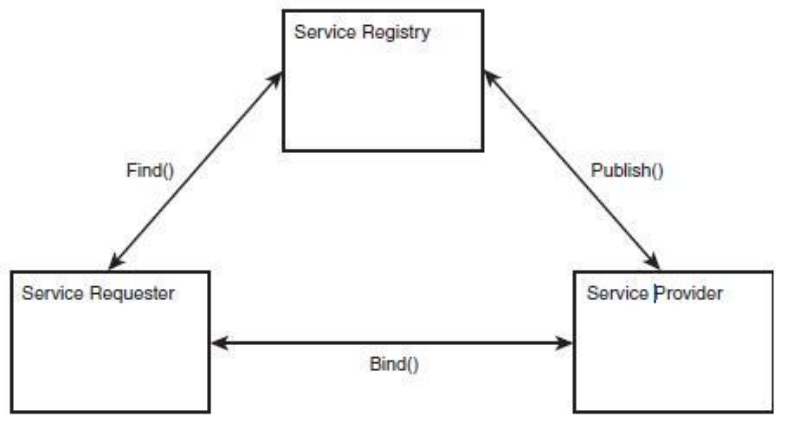

Gambar 2 Arsitektur Umum Web Service [6]

\subsection{2. $X M L$}

Perkembangan jaringan komputer, termasuk internet dan intranet telah memungkinkan pemakai-pemakai mengakses sumber data yang luarbiasa besar.Peningkatan pengaksesan 
basisdata mempunyai dampak praktis yang besar, data dan jasa dapat ditawarkan secara langsung ke konsumen.XML [7] memungkinkan pendeskripsian isi dokumen yang mempercepat penggunaan web untuk aplikasi komersial.

XML telah menjadi sesuatu yang besar di bidang bisnis.XML penting dalam bisnis karena memungkinkan pertukaran data sederhana, standar dan tidak terkait perusahaan tertentu. Data yang sama dapat diakses melalui banyak perangkat seperti browser, handphone, personal data assistant (PDA), dan sebagainya. XML secara esensi merampingkan proses komunikasi antara perusahaan dan konsumen.

\subsubsection{SOAP}

XML saja tidak cukup agar Web Services dapat berkomunikasi dengan aplikasi yang lainya.XML yang digunakan untuk saling bertukar informasi antara Web Servicesdengan aplikasi yang lainya harus menggunakan sebuah format standard yang dapat dimengerti oleh keduanya. SOAP merupakan suatu format standard dokumen berbentuk XML (XML-based mark-up language) yang digunakan untuk melakukan proses request dan responses antara Web Servicesdengan aplikasi yang memanggilnya. Dokumen SOAP digunakan untuk melakukan request disebut dengan SOAP request sedangkan dokumen SOAP yang diperoleh dari Web Services disebut dengan SOAP responses [8].

Sebuah pesan SOAP adalah dokumen XML yang berisi elemen-elemen. Gambaran visual dari elemen-elemen tersebut tersaji dalam Gambar 3.

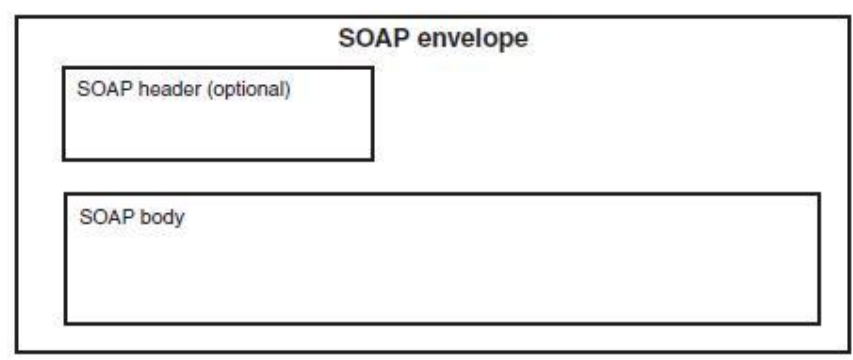

Gambar 3 Elemen-Elemen SOAP [5]

\subsubsection{WSDL}

Sebelum mengakses sebuah Web Servicespastinya perlu mengetahui method-method apa saja yang disediakan oleh Web Servicestersebut, untuk mengetahuinya memerlukan sebuah dokumen yang bernama WSDL. WSDL (Web ServicesDescription Language) [5] adalah sebuah bahasa berbasis XML yang digunakan untuk mendeskripsikan sebuah web service, termasuk didalamnya adalah informasi mengenai operasi yang disediakan oleh web service tersebut berserta dengan tipe parameter yang diperlukan, dan informasi mengenai lokasi akses dari web service tersebut. WSDL memberikan deskripsi service request dengan protokol-protokol yang berbeda.WSDL memfasilitasi komunikasi antar aplikasi. WSDL akan mendeskripsikan apa yang akan dilakukan oleh web service, bagaimana menemukannya dan bagaimana memanfaatkan layanan tersebut.

\subsection{5. $U D D I$}

UDDI (Universal Description, Discovery and Integration) [5] adalah sebuah service registry bagi pengalokasian web service.UDDI mengkombinasikan SOAP dan WSDL untuk pembentukan sebuah registry API bagi pendaftaran dan pengenalan service.

\subsection{PHP Hypertext Preprocessor}

PHP adalah singkatan dari "PHP : Hypertext Preprocessor", yang merupakan sebuah bahasa scripting yang terpasang pada HTML. Program PHP harus diterjemahkan oleh web server sehingga menghasilkan kode HTML yang dikirim ke browser agar dapat 
ditampilkan.Program ini dapat berdiri sendiri ataupun disisipkan diantara kode-kode HTML sehingga dapat langsung ditampilkan bersama kode-kode HTML tersebut.

\section{HASIL DAN PEMBAHASAN}

\subsection{Analisis Kebutuhan}

Analisis kebutuhan (requirement) sistem SI DPterdiri dari dua tipe kebutuhan yaitu kebutuhan fungsional dan kebutuhan non fungsional. Secara umum, kebutuhan non fungsional suatu perangkat lunak terdiri dari empat macam, yaitu: Usability, Reliability, Portability dan Supportability.

\subsection{Aspek Sistem SI DP}

Selain analisis kebutuhan sistem SI DP yang telah dilakukan sebelumnya, ada beberapa aspek yang harus diperhatikan.Aspek ini sangat mempengaruhi pelaksanaan SI DP.Aspek yang mempengaruhi suatu sistem SI DP agar dapat berjalan dengan baik adalah Teknologi, Sosial dan Prosedur operasional.

\subsection{Rancangan Arsitektur Sistem}

Adapun arsitektur umum implementasinya ditunjukkan pada Gambar 4.

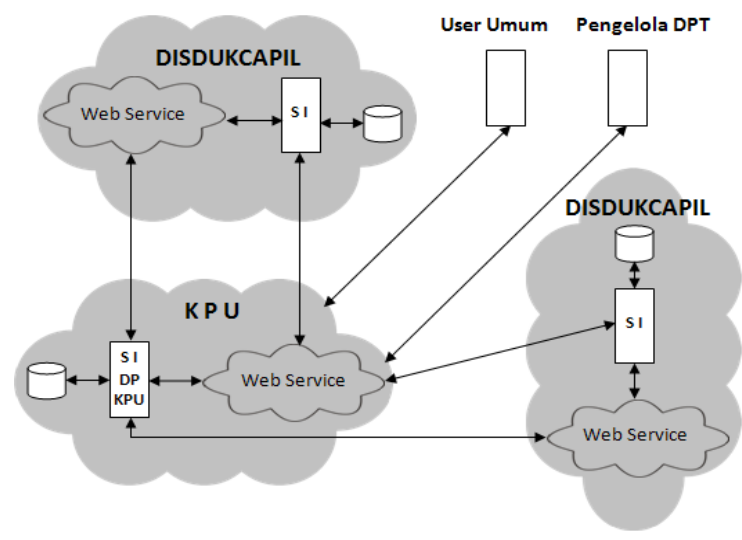

Gambar 4 Arsitektur Sistem DP Terintegrasi

Web service yang disajikan dalam sistem DP terintegrasi ini adalah :

1. Web Service Pemilih

Melalui web service eksternal, dilakukan request terhadap data DP di SI DISDUKCAPIL. Selanjutnya pada server DISDUKCAPIL akan memberikan respon. Rangcangan implementasi web service Pemilih tersebut tersaji dalam Gambar 5.

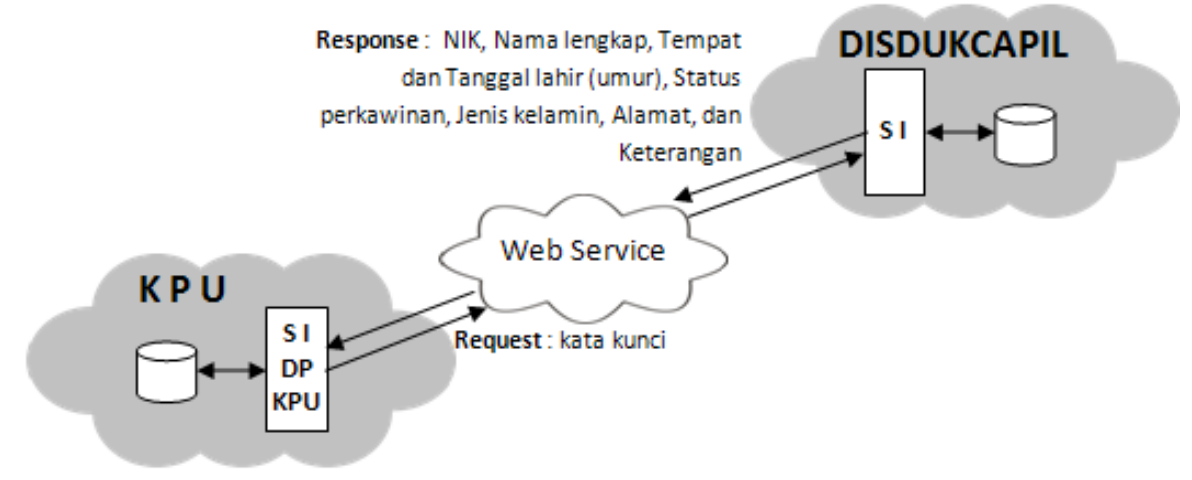

Gambar 5 Rancangan Implementasi Web Service Data Pemilih 
2. Web Service Penduduk

Melalui web service eksternal, dilakukan request terhadap data DP di SI DP. Selanjutnya pada server DP akan memberikan respon. Rangcangan implementasi web service Pemilih tersebut tersaji dalam Gambar 6.

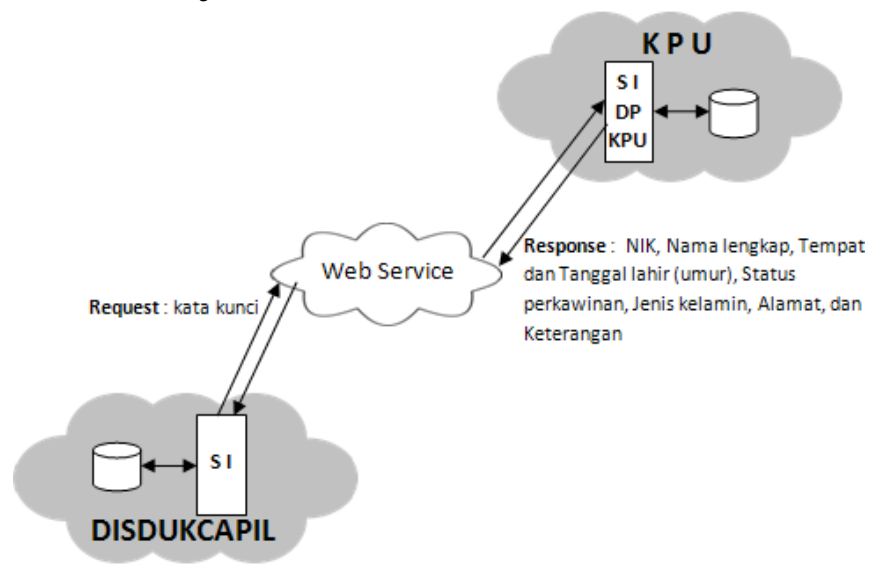

Gambar 6 Rancangan Implementasi Web Service Data Penduduk

\subsubsection{Context Diagram}

Context diagram dari sistem informasi ini terdiri dari empat entitas.Keempat entitas adalah User Umum, Pengelola DP (KPU), KPU Kabupaten/Kota dan DISDUKCAPIL.Rancangan context diagram tersebut disajikan pada Gambar 7.

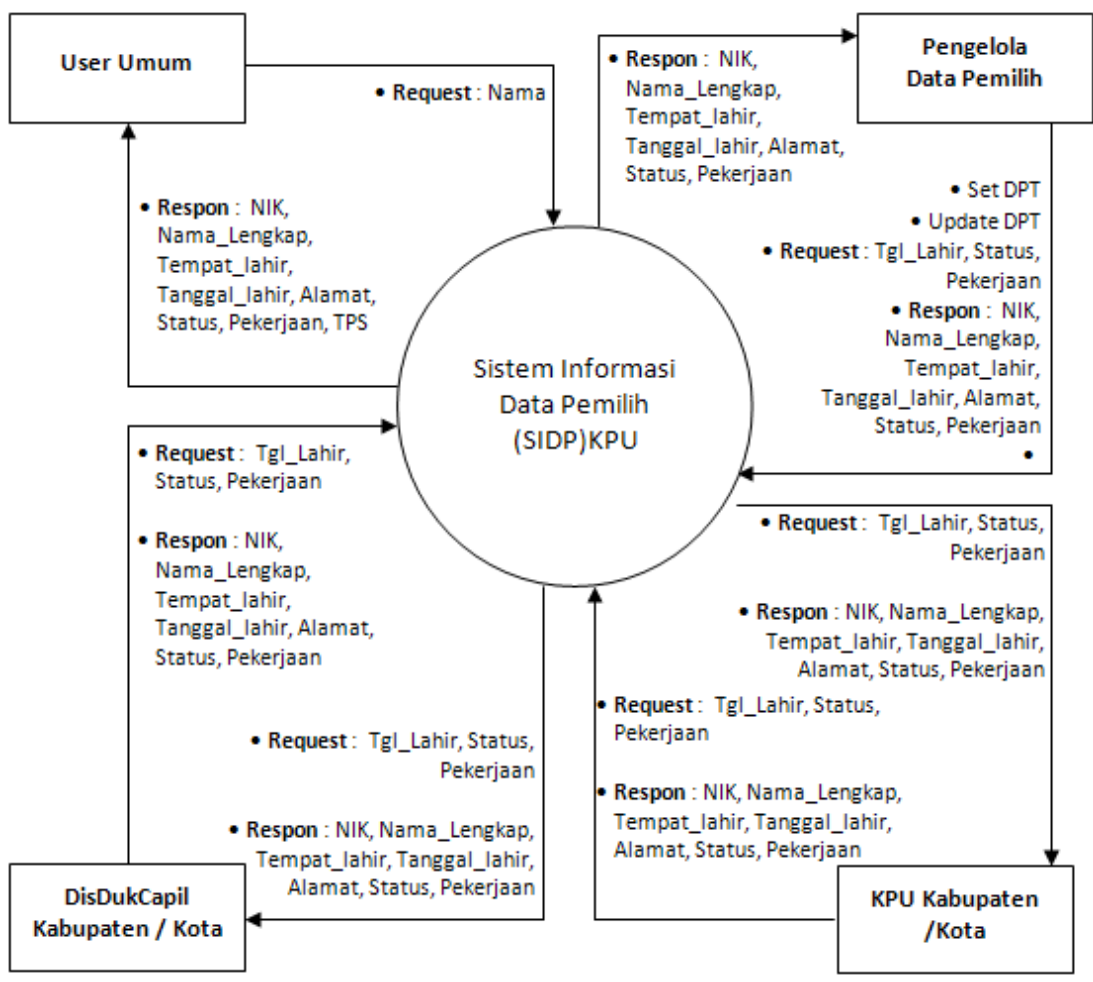

Gambar 7 Context Diagram SI DP

\subsubsection{DFD Level 1}

Dari context diagram, pemodelan dapat disajikan lebih detail dengan DFD Level 1. DFD Level 1 disajikan pada Gambar 8.

IJCCS Vol. 7, No. 1, January 2013: $1-12$ 


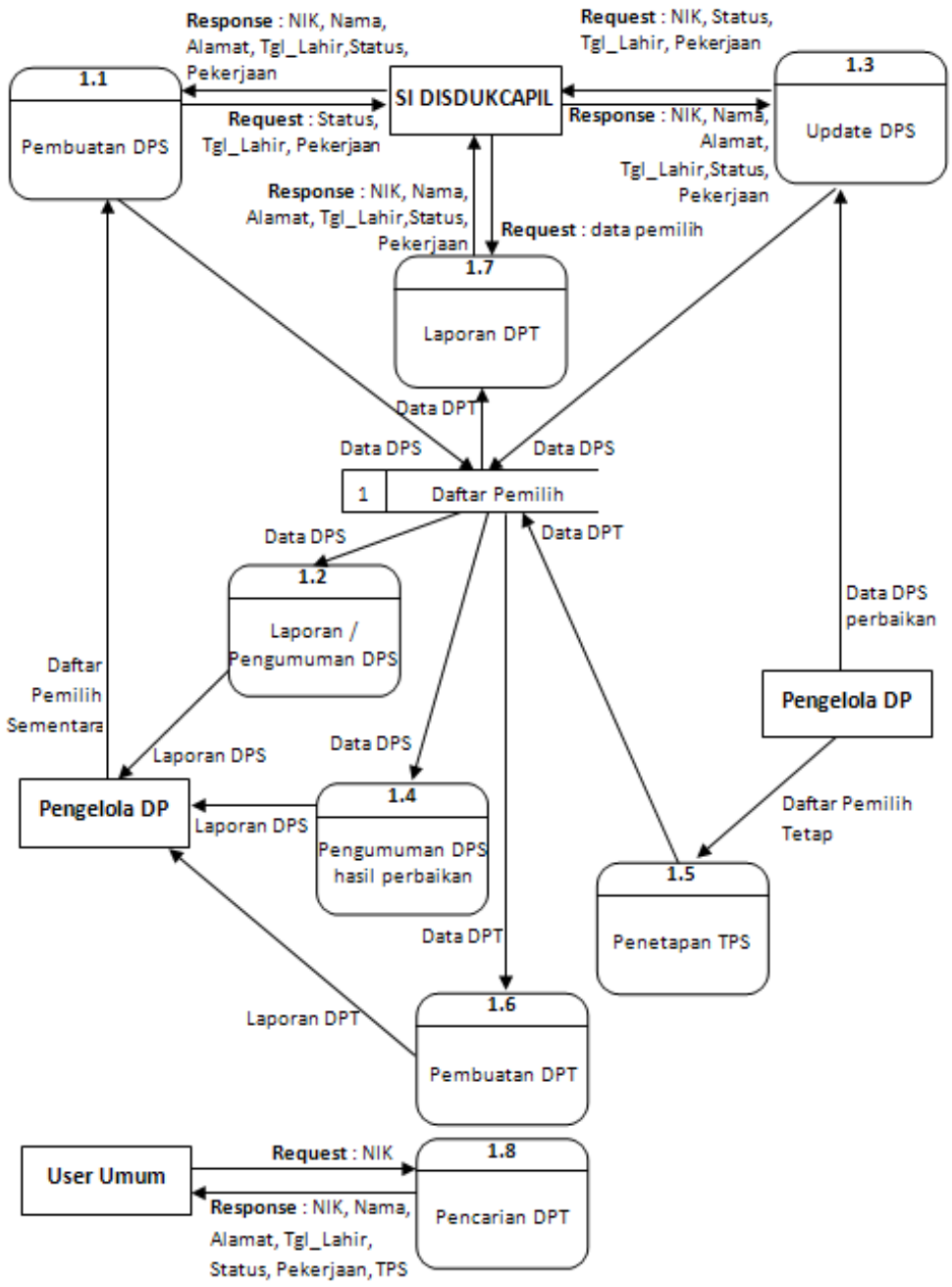

Gambar 8 DFD Level 1 Sistem Informasi DP

\subsection{Pembuatan Web Service}

Pembuatan web service pada penelitian ini merupakan web service yang mengintegrasikan SI DP KPU dengan SI DISDUKCAPIL.

Web service dibuat untuk melakukan integrasi data DP antar instansi.Dalam penelitian ini hanya dilakukan integrasi antara KPU Maros dengan DISDUKCAPIL Kab.Maros.

Web service ini nantinya ditempatkan pada masing-masing instansi dalam hal ini KPUD dan DISDUKCAPIL. Respon-respon akan disesuaikan dengan data yang tersimpan pada masing-masing instansi, SIDP KPU dan SIAK DISDUKCAPIL. Adapun web service yang dibuat dalam web service ini adalah sebagai berikut :

1. Web Service Pemilih

Web service Pemilih ini dibuat untuk menyediakan respon data penduduk pemilih yang ada di DISDUKCAPIL.Data yang dihasilkan meliputi NIK, Nama lengkap, Tempat dan Tanggal lahir (umur), Status perkawinan, Jenis kelamin, Alamat, dan Keterangan. Input variable yang diberikan pada web service ini adalah kata kuncil seputar pemilih yang berupa string. Adapun WSDL yang dihasilkan dari web service ini ditunjukkan pada Gambar 9. 


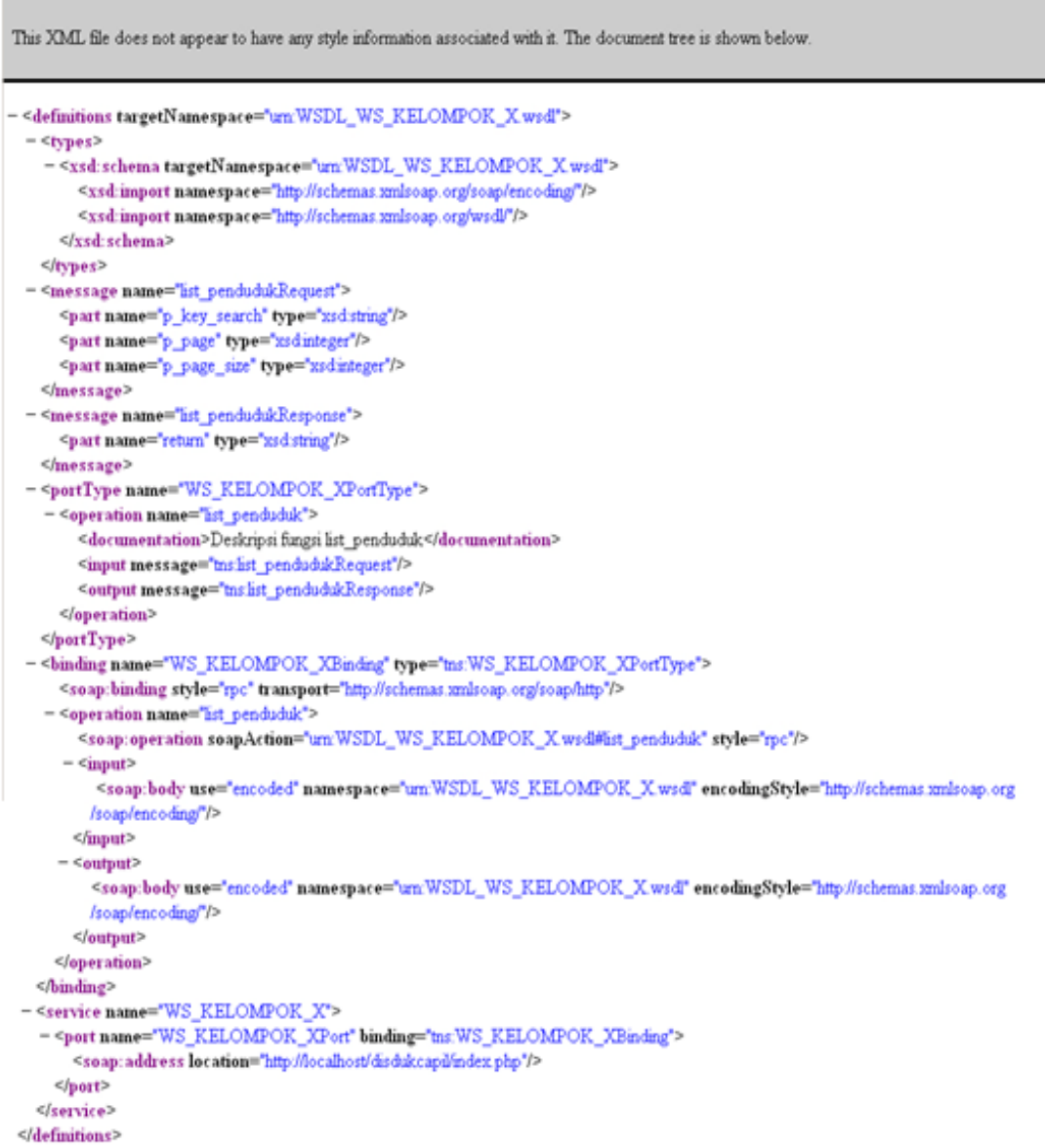

Gambar 9 WSDL Web Service Pemilih

Respon yang dihasilkan tersaji pada Gambar 10.

Mastkan : TGL PILADA $\sqrt{2020-10-10}$ lanja

\begin{tabular}{|c|c|c|c|c|c|c|c|c|c|c|c|c|}
\hline \multicolumn{13}{|c|}{ Tanggal Pemilhes 2020-10-10 } \\
\hline $\begin{array}{c}\text { ID } \\
\text { PDDK }\end{array}$ & NIK & NAML & SEX & $\begin{array}{l}\text { TMPT } \\
\text { LHR }\end{array}$ & TGL LHR & \begin{tabular}{|l} 
ID \\
NIK
\end{tabular} & ALAMLAT & $\begin{array}{c}\text { ID } \\
\text { PEK }\end{array}$ & $\begin{array}{c}\text { ID } \\
\text { WN }\end{array}$ & $\begin{array}{c}\text { ID } \\
\text { DESA }\end{array}$ & $\underset{\text { KFC }}{\text { ID }}$ & $\underset{\text { KAB }}{\text { ID }}$ \\
\hline 11 & 34.11111111 & fra & Iski-laki & sby & $1977-03-31$ & 7 & i & 15 & 4 & 49 & 16 & 5 \\
\hline 12 & 7309010404780002 & Hrenza & Inki-laki & Maros & $1978-04-04$ & 6 & Padangalla & 5 & 4 & 5 & 7 & 5 \\
\hline 13 & 7309015810790006 & 5 Nurbaya & Wanta & Makassar & $1979-10-18$ & 6 & Padangalla & 9 & 4 & 11 & 8 & 5 \\
\hline 14 & 7309015306000003 & $\begin{array}{l}\text { Rozalinda } \\
\text { Nurhameah }\end{array}$ & Wanita & Maros & $2000-06-13$ & 7 & Padangalla & 10 & 4 & 11 & 8 & 5 \\
\hline 15 & 7309012912010003 & $\begin{array}{l}\text { Syaknul } \\
\text { Nurhamstah }\end{array}$ & Iaki-laki & Maros & $2001-12-29$ & 7 & Padangalla & 10 & 4 & 11 & 8 & 5 \\
\hline 16 & & $\begin{array}{l}\text { Sni Muffida } \\
\text { Nurhamrah }\end{array}$ & Wanta & Maros & $2002-12-31$ & 7 & Padangalla & 16 & 4 & 5 & 7 & 5 \\
\hline
\end{tabular}

Gambar 10 Hasil Respon Data Pemilih

2. Web Service Penduduk

Web service Penduduk ini dibuat untuk menyediakan respon data penduduk pemilih yang terdaftar dalam DPT KPUD. Data yang dihasilkan meliputi NIK, Nama lengkap, Tempat dan Tanggal lahir (umur), Status perkawinan, Jenis kelamin, Alamat, dan Keterangan. Input variable yang diberikan pada web service ini adalah kata kunci seputar penduduk pemilih yang berupa data string.

Web service Penduduk tersebut ditempatkan pada SI DP dengan nama file ws_server.php. Adapun WSDL yang dihasilkan dari web service ini ditunjukkan pada Gambar 11.

IJCCS Vol. 7, No. 1, January 2013: $1-12$ 


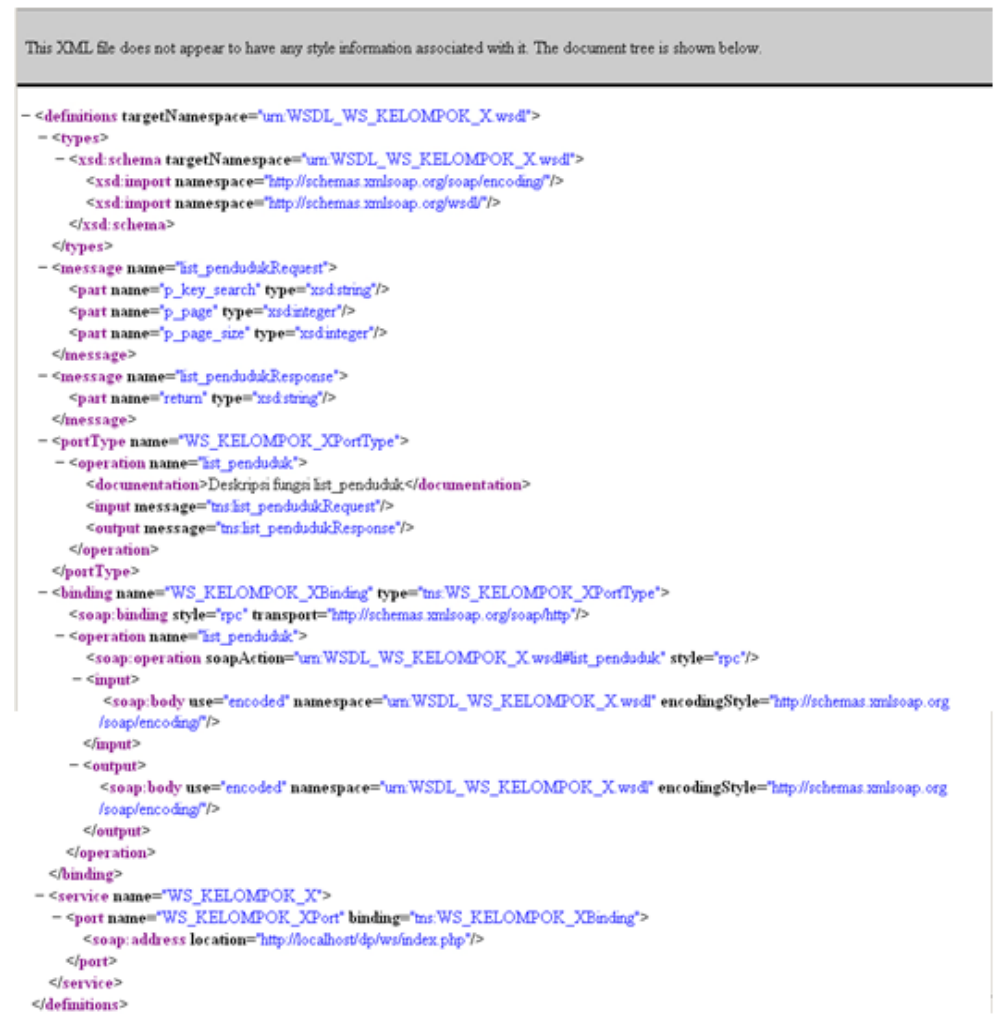

Gambar 11 WSDL Web Service Penduduk

Respon yang dihasilkan tersaji pada Gambar 12.

\begin{tabular}{|c|c|c|c|c|c|c|c|c|c|c|c|c|}
\hline \multicolumn{13}{|c|}{ Daftar Penduduk Pemilh Kabupaten Maros } \\
\hline $\begin{array}{c}\text { ID } \\
\text { PDDK }\end{array}$ & NIK & NAMLA & SEX & \begin{tabular}{|l} 
TMPT \\
LHR
\end{tabular} & TGL LHR & $\begin{array}{c}\text { ID } \\
\text { NIK }\end{array}$ & ALAMAT & $\begin{array}{c}\text { ID } \\
\text { PEK }\end{array}$ & $\begin{array}{l}\text { ID } \\
\text { WN }\end{array}$ & $\begin{array}{c}\text { ID } \\
\text { DESA }\end{array}$ & $\underset{\mathbf{K F C}}{\mathrm{ID}}$ & $\underset{\mathrm{KAB}}{\mathrm{ID}}$ \\
\hline 11 & 34.11111111 & frees nas & & sby & $1977-03-31$ & 7 & II & 15 & 4 & 49 & 16 & 5 \\
\hline 12 & 7309010404780002 & Hamza & & Maros & $1978-04-046$ & & Padangalla & 5 & 4 & 5 & 7 & 5 \\
\hline 13 & 7309015810790006 & Nurbaya & & 24akassar & $1979-10-186$ & & Padangalla & 9 & 4 & 11 & 8 & 5 \\
\hline 14 & 7309015306000003 & $\begin{array}{l}\text { Rozaleda } \\
\text { Nurhameah }\end{array}$ & & Maros & $2000-06-13$ & 7 & Padangalla & 10 & 4 & 11 & 8 & 5 \\
\hline 15 & 7309012912010003 & $\begin{array}{l}\text { Syateul } \\
\text { Nurhameah }\end{array}$ & & Maros & $2001-12.29 \mid 7$ & 7 & Padangalla & 10 & 4 & 11 & 8 & 5 \\
\hline 16 & & $\begin{array}{l}\text { Sin Mieffida } \\
\text { Nurhameah }\end{array}$ & & Maros & $2002-12-317$ & 7 & Padangalla & 16 & 4 & 5 & 7 & 5 \\
\hline
\end{tabular}

Gambar 12 Hasil Respon Data Penduduk

\subsection{Pembuatan SI DP}

Sistem Informasi DP merupakan aplikasi yang digunakan untuk pengelolaan data DP.Aplikasi ini secara umum meliputi pengelolaan DPS, DPS hasil perbaikan dan DPT. Aplikasi ini dilengkapi juga dengan layanan pencarian pemilih pada DPT berdasarkan suatu kata kunci yang mengarah ke pemilih dalam DPT.

\subsubsection{Pembuatan User Interface Pengelola DP}

Layanan Pengelola DP pada Sistem Informasi DP digunakan untuk mendapat DP4 untuk dijadikan sebagai DPS awal. Web service pemilih digunakan untuk mengambil seluruh data penduduk dari database yang ada pada SI DISDUKCAPIL kemudian diseleksi dengan syarat berdasarkan status, usia dan pekerjaan.

Proses awal, disediakan input tanggal pilkada, tanggal pilkada nantinya akan digunakan untuk me-request data pemilih pada SI DISDUKCAPIL melalui web service pemilih untuk mendapatkan data pemilih. Hasil respon web service pemilih tersebut dimasukkan ke tabel 
Pemilih. Proses kedua menampilkan pada halaman web menjadi pengumuman DPS tahap pertama seperti tersaji pada Gambar 13.

\begin{tabular}{|c|c|c|c|c|c|c|c|c|c|c|c|c|}
\hline \multicolumn{2}{|c|}{ 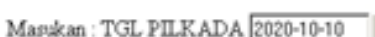 } & $0-10-10$ & & & & & & & & & & \\
\hline \multicolumn{13}{|c|}{ Daftar Penduduk Peminh Kabupaten Maros } \\
\hline \multicolumn{13}{|c|}{ Tanggal Pemillina 2020-10-10 } \\
\hline $\begin{array}{c}\text { ID } \\
\text { PDDK }\end{array}$ & NIK & NAMA & SEX & $\begin{array}{l}\text { TMPT } \\
\text { LHR }\end{array}$ & TGL LHR & $\begin{array}{c}\text { ID } \\
\text { NIK }\end{array}$ & AL.AMLAT & \begin{tabular}{|c|} 
ID \\
PEK
\end{tabular} & $\begin{array}{c}\mathrm{ID} \\
\mathrm{WN}\end{array}$ & $\underset{\text { DESA }}{\text { ID }}$ & $\begin{array}{c}\mathrm{ID} \\
\mathrm{KEC}\end{array}$ & $\underset{\text { KAB }}{\mathrm{ID}}$ \\
\hline 11 & 34.11111111 & fra & Laki-laki & sby & $1977-03-31$ & 7 & in & 15 & 4 & 49 & 16 & 5 \\
\hline 12 & 7309010404780002 & Hanza & Laki-laki & Maess & $1978-04-04$ & 6 & Padangala & 5 & 4 & 5 & 7 & 5 \\
\hline 13 & 7309015810790006 & Nurbaya & Wanita & Makassar & $1979-10-18$ & 6 & Padangala & 9 & 4 & 11 & 8 & 5 \\
\hline 14 & 7309015306000003 & $\begin{array}{l}\text { Rozalinda } \\
\text { Nurhamenat }\end{array}$ & Warita & Maros & $2000-06-13$ & 7 & Padangalla & 10 & 4 & 11 & 8 & 5 \\
\hline 15 & 7309012912010003 & $\begin{array}{l}\text { Syaknul } \\
\text { Nurhamzah }\end{array}$ & I.akj-laki & Maros & $2001-12-29$ & 7 & Padangalla & 10 & 4 & 11 & 3 & 5 \\
\hline 16 & & $\begin{array}{l}\text { Sri Muesda } \\
\text { Nurhamzah }\end{array}$ & Wanta & Maros & $2002-12-31$ & 7 & Padangala & 16 & 4 & 5 & 7 & 5 \\
\hline
\end{tabular}

Gambar 13 Tampilan Proses Awal Pembuatan DPS

1. Selanjutnya proses ketiga akan dilakukan tahapan update DPS. Tahap kedua pihak petugas akan melakukan update data pemilih sesuai hasil pemutakhiran data di lapangan dengan user interface (UI) seperti tersaji pada Gambar 14 dan Gambar 15.

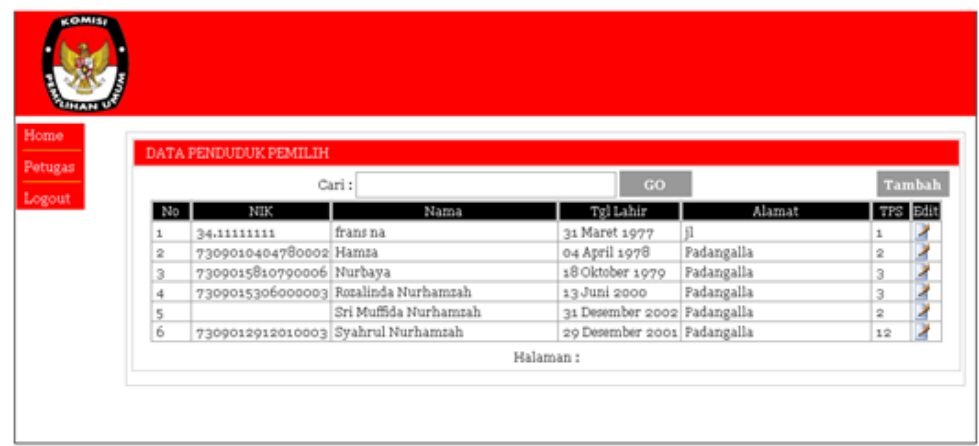

Gambar 14 Halaman Data Penduduk Login Petugas

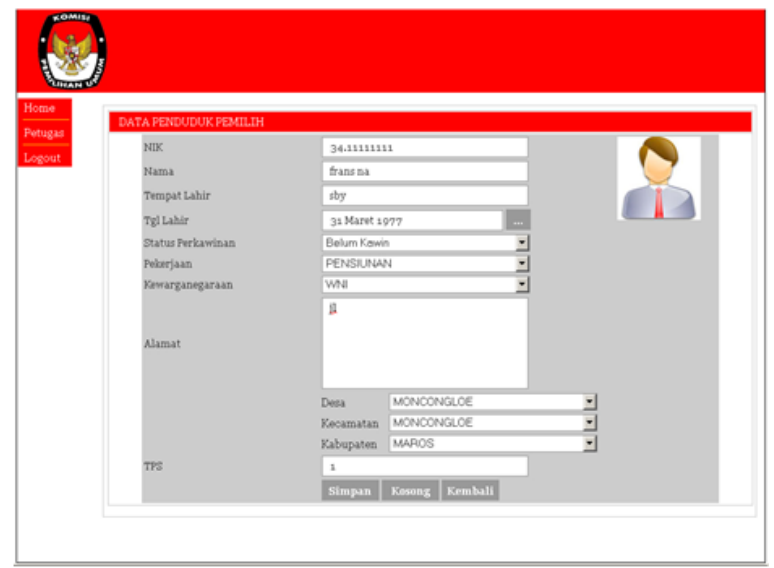

Gambar 15 Halaman Edit Data Login Petugas

\subsubsection{Pembuatan Layanan SI DISDUKCAPIL}

Layanan SI DISDUKCAPIL digunakan untuk mengambil data pemilih dari SI DP. Dalam pembuatan layanan SI DISDUKCAPIL ini melibatkan web service Penduduk. Hasil respon web service pemilih tersebut dimasukkan ke tabel Penduduk. Selanjutnya akan ditampilkan pada halaman web menjadi laporan penduduk pemilih untuk dijadikan update data kependudukan, tampilannya dapat dilihat pada Gambar 16.

IJCCS Vol. 7, No. 1, January 2013: $1-12$ 


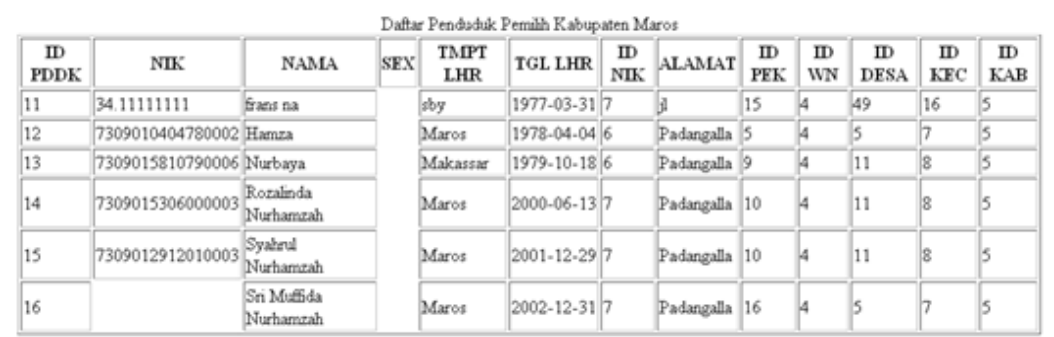

Gambar 16 Tampilan Proses Pelaporan Data Pemilih

\subsubsection{Pembuatan User Interface Pemilih}

Pada laporan daftar penduduk pemilih, pertama user harus login dengan user name dan password yang telah disediakan, selanjutnya akan ditampilkan daftar pemilih dalam DP4, DPS, DPS hasil perbaikan dan DPT yang masing-masing diperoleh dari Tabel Pemilih pada SI DP, yang ditampilkan berupa informasi NIK, Nama Pemilih, Tanggal Lahir, Alamat dan TPS. Selanjutnya disediakan layanan untuk mencari nama pemilih. Tampilan laporan tersebut tersaji pada Gambar 17 dan Gambar 18.

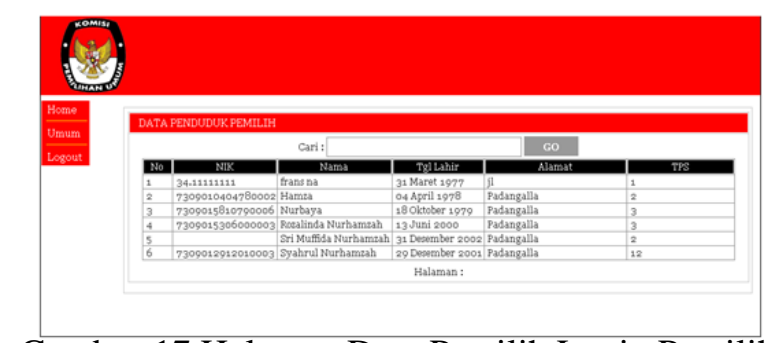

Gambar 17 Halaman Data Pemilih Login Pemilih

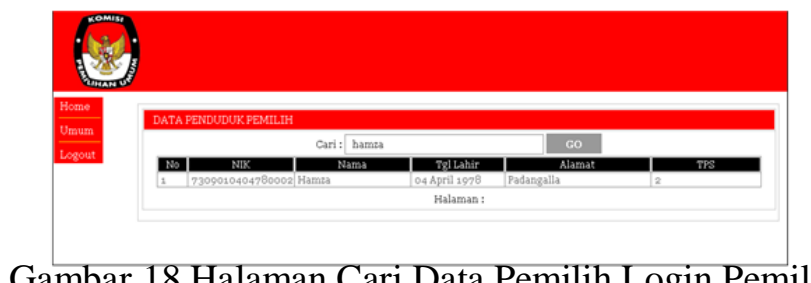

Gambar 18 Halaman Cari Data Pemilih Login Pemilih

\section{KESIMPULAN}

Mengacu pada tujuan tesis ini dan hasil pengujian, maka dapat diambil kesimpulan sebagai berikut :

1. Adanya syarat model dalam web service pada prototipe integrasi data penduduk daftar pemilih tetap di SIAK DISDUKCAPIL dengan SI DP KPU Kabupaten Maros.

2. Model Sistem Informasi Daftar Penduduk (SI DP) yang dihasilkan tetap mengacu pada syarat yang memenuhi penetepan DPT secara konvensional, secara umum fokus pembahasan dititikberatkan pada faktor teknologi.

3. Telah dikembangkan Prototie SI DP yang memanfaatkan teknologi web service untuk integrasi data antara SI DP dengan SI DISDUKCAPIL, dengan berpedoman pada kebutuhan Fungsional dan kebutuhan Non-Fungsional.

4. Berdasarkan hasil pengujian didapati Sistem Informasi DP telah berjalan sesuai analisis fungsional dan dapat digunakan untuk manajemen DP. SI DP yang dibangun dalam penelitian ini telah mampu mengintegrasikan SI DP KPU dengan SI DISDUKCAPIL. 
5. Dengan memanfaatkan Internet dan Aplikasi SI DP (Website) maka memberikan alternatif lain dalam media publikasi, disamping tetap menggunakan media publikasi yang telah digunakan selama ini.

\section{SARAN}

Berdasarkan pada pengujian yang telah dilakukan pada sistem yang dibuat masih banyak kekurangan dan kelemahan sehingga perlu dikembangkan lagi agar kinerjanya menjadi lebih baik lagi, oleh karena itu saran yang diberikan adalah sebagai berikut :

1. Agar Peneliti berikutnya dapatmeneliti lebih lanjut verifikasi dokumen dukungan bakal calon pasangan perseorangan yang didasarkan pada DPT yang ada, sehingga permasalahan yang sering muncul dalam PILKADA dan PEMILU dapat diminimalisir.

2. Agar Peneliti berikutnya dapatmenambah fitur, sehingga semakin meningkatkan kemampuannya dalam menyajikan informasi yang ada didalamnya.

\section{UCAPAN TERIMAKASIH}

Penulis mengucapkan terima kasih kepada berbagai pihak yang telah memberi dukungan moril dan finansial terhadap penelitian ini.

\section{DAFTAR PUSTAKA}

[1] KPU, 2010, Peraturan KPU Nomor 13 Tahun 2010, Jakarta.

[2] Pemerintah RI,2006, Undang-Undang Republik Indonesia Nomor 23 Tahun 2006 Tentang Administrasi Kependudukan, Jakarta.

[3] Pemerintah RI, 2007 , Undang-Undang Nomor 22 Tahun 2007 tentang Penyelenggara Pemilihan Umum, Jakarta.

[4] Abdullah, Rozali, 2010,"Ada Apa dengan DPT?",http://www.jambiekspres.co.id/ opini/10282-ada-apa-dengan-dpt.html

[5] Potts, Stephen dan Kopack, Mike, 2003, Sams Teach Yourself Web Services in 24 Hours, Sams Publishing, Indianapolis, Indiana, USA.

[6] W3C Working Group, 2004, Web Services Architecture, http://www.w3.org/TR/2004/NOTE-ws-arch-20040211/

[7] Hariyanto, Bambang, 2004, Sistem Manajemen Basisdata (pemodelan, perancangan dan terapannya), Informatika, Bandung.

[8] W3C Working Group, 2000, Simple Object Access Protocol (SOAP) 1.1, http://www.w3.org/TR/2000/NOTE-SOAP-20000508 